\title{
(6) OPEN ACCESS \\ Respiratory and allergic health effects in a young population in proximity of a major industrial park in Oman
}

\author{
Adil Alwahaibi, Ariana Zeka
}

Institute for the Environment, Brunel University London, London, UK

\section{Correspondence to} Dr Adil Alwahaibi, Institute for the Environment, Brunel University London, Uxbridge, Middlesex, London UB8 3PH, UK Adil.Al-Wahaibi@brunel.ac.uk

Received 9 February 2015 Revised 2 August 2015 Accepted 10 August 2015 Published Online First 10 September 2015

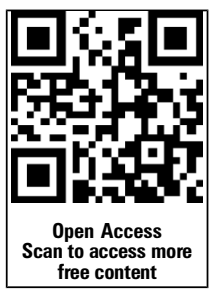

CrossMark

To cite: Alwahaibi A,

Zeka A. J Epidemiol

Community Health

2016:70:174-180

\section{ABSTRACT}

Background Sohar industrial zone (SIZ), Oman, which started operating in 2006, contains many industries that potentially affect the health of the local population. This study's aim was to evaluate the health effects in a young population living near SIZ.

Methods Patient visits to state health clinics for acute respiratory diseases (ARD), asthma, conjunctivitis and dermatitis were obtained for the period of 2006 to 2010 , for children ages $<20$ years old, for two large provinces around SIZ. Three exposure zones were defined on the basis of the distance from SIZ determined as: $\leq 5$, $>5$ to $10, \geq 20 \mathrm{~km}$ to represent high, intermediate and control exposure zones, respectively. Age-specific and gender-specific monthly counts of visits were modelled using generalised additive models controlling for time trends. The high and intermediate exposure zones were later combined together due to the similarity of associations. Exposure effect modification by age, gender and socioeconomic status (SES) was also tested.

Results Living within $10 \mathrm{~km}$ from SIZ showed a greater association with $A R D$ (risk ratio $(R R)=2.5 ; 95 \% C l=2.3$ to 2.7$)$, asthma $(\mathrm{RR}=3.7 ; 95 \% \mathrm{Cl}=3.1$ to 4.5$)$, conjunctivitis ( $R R=3.1 ; 95 \% \mathrm{Cl}=2.9$ to 3.5$)$ and dermatitis ( $R R=2.7 ; 95 \% \mathrm{Cl}=2.5$ to 3.0 ) when compared with the control zone. No differences in associations were found for gender and SES groups; greater effects were noticed in the $\leq 14$-year-old group for asthma.

Conclusions This is the first study conducted in Oman to examine the health effects of a young population living near an industrial park. We hope that these findings will contribute in future developments of environmental health policies in Oman.

\section{INTRODUCTION}

The accelerated global industrialisation trends during the past century have raised many concerns about the potential environmental health problems that might be caused as a result. In 2012, it was estimated that seven million global deaths per year were attributed to air pollution. ${ }^{1}$ Enhanced by the lack of strict environmental controls and public health systems in developing countries, industrialisation has shifted in recent decades from developed to developing countries, deteriorating environmental and public health situations in the latter. $^{2}$ A recent report of the WHO shows that $25 \%$ of the mortality in developing countries is environmentally related; this estimate is $17 \%$ in developed countries. Children are particularly susceptible to environmental exposures, ${ }^{3}$ and the WHO's recent estimates show that $36 \%$ of the global child mortality was attributable to environmental causes. 4

Oman, one of the currently fast developing economies, has also initiated a heavy industrialisation movement to supplement its national resources, leading to a rapid establishment of several major industrial parks in the country. One of these is the Sohar industrial zone (SIZ), a large petrochemical and heavy metal industrial complex. The establishment of this complex near a densely populated residential area consequently raised great health, environmental and financial concerns from its surrounding residents. SIZ, with its anticipated expansions in the near future, necessitates a parallel community health assessment of the population of the residential area around it. Evidence elsewhere shows that children living near industrial establishments have a higher risk of adverse health outcomes when compared with those living away. ${ }^{5-10}$ However, global evidence on the risk of adverse health of young populations living in proximity to industries is still limited, as highlighted in a recent review by Pascal et al. ${ }^{11}$

A recent study, also the first environmental epidemiological study in Oman, showed increased risk of respiratory and allergic disease in an adult population living in proximity to SIZ. ${ }^{12}$ No similar study has been carried out in Oman to assess the link between the recent industrial developments and child health. The aim of this study was to examine the relationship between adverse health and proximity to SIZ in a young population.

\section{METHODOLOGY \\ Population data}

Daily patient visits to state health clinics in the two provinces around SIZ, Sohar and Liwa, were obtained from the National Al-Shifa electronic system, Omani Ministry of Health $(\mathrm{MoH})$ for the period of 1 January 2006 to 31 December 2010. Information for each patient visit included the consultation date, a unique patient identification number, age, village, health centre and the diagnosis based on the International Classification of Diseases 10th Revision (ICD-10). Ethical approval for this study was obtained from the $\mathrm{MoH}$ and Brunel University Ethical Committee.

According to previous evidence on the health effects of air pollution in young populations, we selected to study respiratory and allergic diseases. Respiratory diseases included: acute respiratory diseases (ARD) defined as upper (ICD-10: J0-J06), other acute lower respiratory infections (ICD-10: J20-J22) and pneumonia (ICD-10: J12-J18); and 
asthma (ICD-10: J45 and J46). Allergic diseases included disorders of the conjunctiva (ICD-10: H10-H13), dermatitis (ICD-10: L20-L30) and eczema (ICD-10: L50-L54).

Area-specific population by age and gender for each village was obtained from the Omani National Census of 2010, and was used as an offset in the model. The education and occupational status of the residents was also obtained from the same source and utilised to define socioeconomic status (SES). Daily temperature and wind data were provided by the Omani Department of Meteorology for the entire study period.

\section{Definition of health outcomes variables}

For this study, it was important to distinguish between visits for a 'new event' and a 'follow-up' for the selected diseases. In previous epidemiological studies, definitions of a 'new case' of ARD in children vary from 1 week disease-free duration to up to 3 months. ${ }^{13}{ }^{14}$ For asthma, many epidemiological studies define a 'new asthma attack' in children as an attack happening after one attack-free year. ${ }^{15}$ Other studies have used periods of 1 day, ${ }^{16} 2$ weeks, ${ }^{17}$ up to 1 month attack-free for their definitions. ${ }^{18}$ For allergic diseases, several epidemiological studies extended their definition of a 'new event' from 10 disease-free days ${ }^{19}$ to up to 1 year. ${ }^{20}$ From the above discussion, and also to ensure sufficient sample size for the analysis, we used a 1 month period to define 'new events' for ARD, asthmatic and allergic diseases. Follow-up visits were defined as any patient visit occurring between two 'new events'.

\section{Site characteristics}

SIZ is composed of the Sohar industrial port (SIP) and the Sohar industrial estate (SIE). SIP contains a petrochemical industrial complex and an iron smelter. The petrochemical complex started to operate with an oil refinery in 2006, and expanded in the following 3 years to include the polypropylene, methanol, formaldehyde, urea and aromatics industries. The main industry in SIE is an aluminium smelter, which started to operate in 2008. Owing to its early operation date and subjectively visible plumes, we considered the oil refinery (in SIP) as the centre point of the industrial park used in the exposure assessment method.

\section{Exposure assessment}

Air pollution monitoring and measurements in the area were not available for the study period. We employed a proximity method to classify exposure of the study population according to their distance from the source of the industrial pollution. The proximity method has been used frequently in many influential environmental epidemiology studies with considerable impact on public health practices and policies. ${ }^{5}{ }^{21-23}$ The method is also used by many environmental regulatory bodies to outline environmental policies, for example, the US Environmental Protection Agency environmental exposure risk assessment framework, ${ }^{24}$ and the UK Health and Safety Excusive in their planning advice for land use near a major hazard. ${ }^{25}$ The method has also been used in the quick assessments of industrial accidents, ${ }^{26}$ and in environmental justice studies which often apply this method in their assessment of environmental inequality. ${ }^{27}$

To assist us in determining the exposure categories, we reviewed previous relevant epidemiological and policy studies. In some of these studies, the decision of the minimum distance for the proximity method was arbitrary, ${ }^{28}{ }^{29}$ using the residents' complaints of pollutant odours ${ }^{22}$ or determined by environmental measurements. ${ }^{30}$ Definitions of exposure categories in these studies varied from a 5 to $20 \mathrm{~km}$ radius from the industries of concern. ${ }^{11} 2231$ Additionally, we utilised several examples of international housing policies, which recommend the minimal safe distance of housings from industrial areas, generally at $>2 \mathrm{~km} .{ }^{32}$

Taking into consideration this previous evidence and to increase the power of the study, we decided on an incremental distance of $5 \mathrm{~km}$ from the refinery to classify the exposure area around SIZ. Three exposure zones were defined: high, for those living $\leq 5 \mathrm{~km}$ from the refinery; intermediate, those living within $>5$ to $10 \mathrm{~km}$ from the refinery; and control zone as living $\geq 20 \mathrm{~km}$ from the refinery. There were no villages located between 10 and $20 \mathrm{~km}$ from the refinery; therefore, this distance was not represented in the study (figure 1). The use of only state health data resulted in a small number of cases from Sohar city, the main metropolitan area of the study provinces. In its latest statistics, $\mathrm{MoH}$ has registered 51 private health clinics in the study area, out of which $94 \%$ were located in Sohar city. Therefore, the city was excluded from the analysis.

To ensure validity of our proximity exposure definitions, we constructed monthly wind roses for the study period using wind speed and direction. The prevailing winds pointed to the west during summer and September, suggestively carrying the pollutants farther inland. Wind roses pointed towards the seaside in winter and November, and had no major direction in the remaining months. This indicated that during summer and September, the high and intermediate exposure zones could most likely reveal similar pollutant patterns.

We also tested a dispersion model of $\mathrm{SO}_{2}$ emitted from the oil refinery for a very limited period of emission data on pollutant concentrations (between 1 and 15 January 2008), and other emission parameters including stack parameters such as number of stacks, location, height and diameter, emission rate, temperature and velocity. The model suggested a relative change of two to four times in the predicted $\mathrm{SO}_{2}$ concentrations for distances $5-10 \mathrm{~km}$, supporting our proximity exposure classification.

\section{Statistical analysis}

Monthly event counts were modelled using a generalised additive model. Modelling diagnostics (Akaike's Information Criterion) suggested the use of a negative binomial distribution to control for the overdispersion in the data. Time, as a month number, was defined as a continuous variable, and smoothing splines were applied to capture the non-linear seasonal and longer term trends in the selected diseases. Positive autocorrelation was detected and controlled with an autocorrelation structure. We defined three age groups for the analyses: infants as $\leq 1$ year old, children as $>1$ to $\leq 14$ and young adults as $>14$ to $<20$. Exposure zones (with control zone as the reference) were coded as factors in the models. The logarithms of gender and age group-specific population data were used as an offset in the model.

Mean daily temperature, season and individual years were tested as potential confounders, and were not found to affect the exposure-health relationship. This lack of effect could partially be due to the control for time by smoothing function in the model.

Risk ratio (RR) for the different exposure zones was calculated as $\exp ^{(\beta 1)}$ and the $95 \%$ CI levels were calculated using the formula: $\exp ^{(\beta 1 \pm 1.96 \times \mathrm{SE})}$. All statistical analyses were carried out using R software V.3.0.0.

Owing to the similarities of the RR between the high and intermediate exposure zones, further models were carried out combining the two exposure zones. This was also supported by 


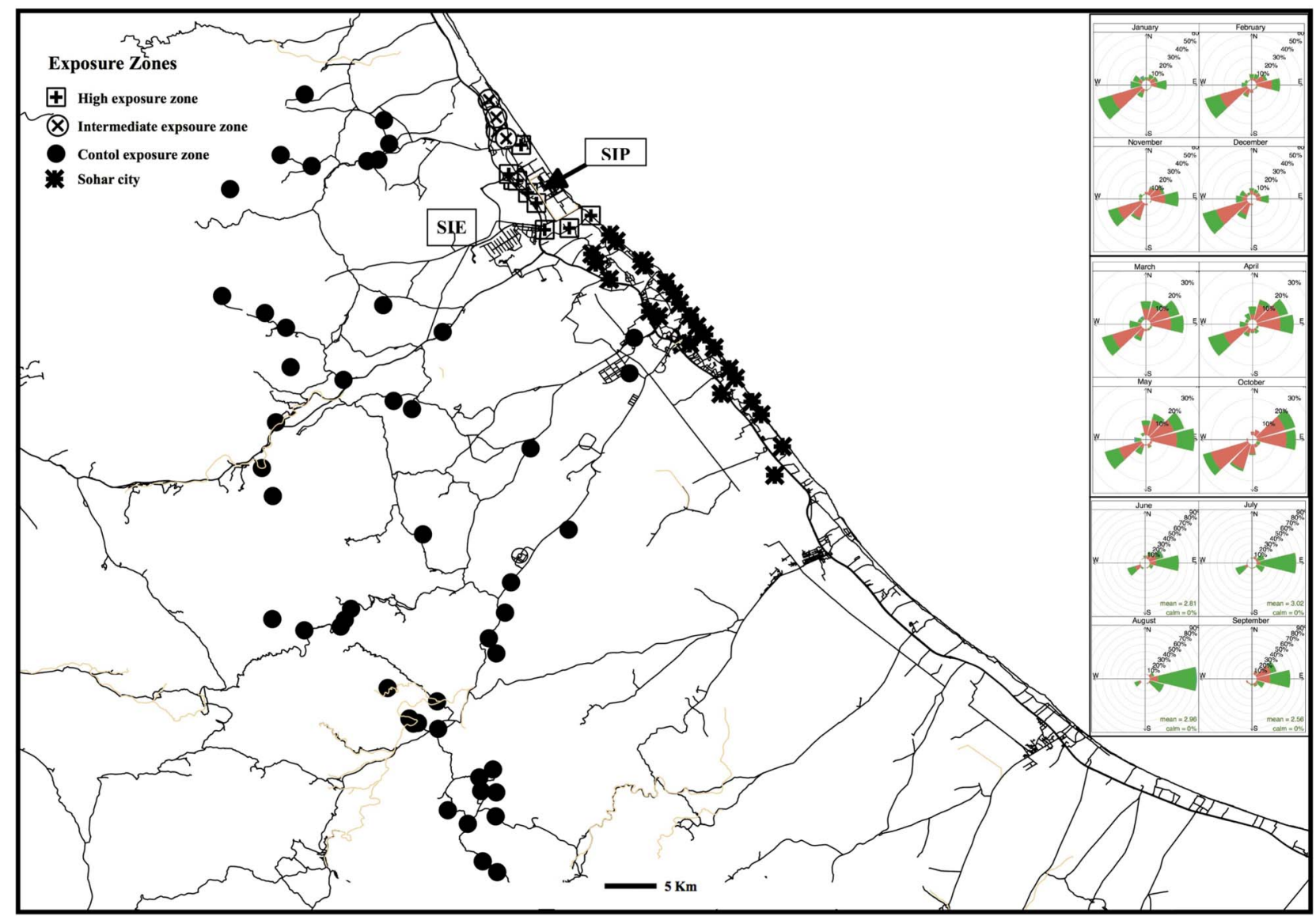

Figure 1 The location of the villages and the industrial zones in the study area. The approximate location of the villages is illustrated. There are no villages located in the area $10-20 \mathrm{~km}$ from the refinery. The wind direction is illustrated by the wind rose diagram. SIP, Sohar industrial port; SIE, Sohar industrial estate.

the similarity of the likely pollutant spread between the two exposure zones, as suggested by the wind roses and dispersion model.

\section{Sensitivity analysis}

To further explore the relationship between exposure and the studied diseases, monthly follow-up frequencies for ARD and asthma were also modelled, using the same model structure and stratified according to age and gender groups.

Assessment of exposure effect modification by age, gender and SES was conducted. SES for each village was determined as the proportions of the total adult population with 'no education', 'high education' and 'employment', which are representatives of the parents' education and employments. The 'high education' index was determined as receiving a bachelor's degree or above. These indicators were assigned to the study population based on village residency. The distributions of each SES index, across all 59 villages, were divided into two strata: below and above 50\%. SES stratified analyses were only carried out for $\mathrm{ARD}$, due to insufficient numbers for other disease definitions.

\section{RESULTS}

The total number of visits for the selected diseases was 197263 . The total population-at-risk of census 2010 was 25215 (table 1). A greater proportion of males in the study population was noted in particular among the ages $>1$ to $<20$ years, and it was more pronounced in the high exposure group. A similar pattern of unequal gender distribution was observed in the population-at-risk. A small number of asthma cases was noted in the infants age group.

The results of the model analysis for the association of the number of 'new visits' for the selected diseases and exposures are presented in table 2. High and intermediate exposure zones had greater effects for all diseases when compared with the control exposure zone. The consistency in the similarity of the associations for the two exposure zones suggested the feasibility of combining them into one zone of $\leq 10 \mathrm{~km}$ radius from the oil refinery.

Table 3 shows the results of the analysis combining the high and intermediate exposure zones stratified by age category, gender and SES for ARD. Positive associations for all diseases in the combined exposure zone were observed, compared with the control exposure zone. The findings suggested no gender difference in exposure effects and no difference by age for ARD, conjunctivitis and dermatitis. Greater associations were observed for asthma among those aged $\leq 14$ years. No differences in associations for ARD were found for any of the SES definitions.

Table 4 shows the results of the model analysis for the follow-up frequencies of ARD and asthma. Increased follow-up frequencies were observed in the combined exposure zone when compared with the control.

\section{DISCUSSION}

This study was carried out to investigate the relationship between adverse health effects in a young population living in 
Table 1 Characteristics of the study population for each exposure zone

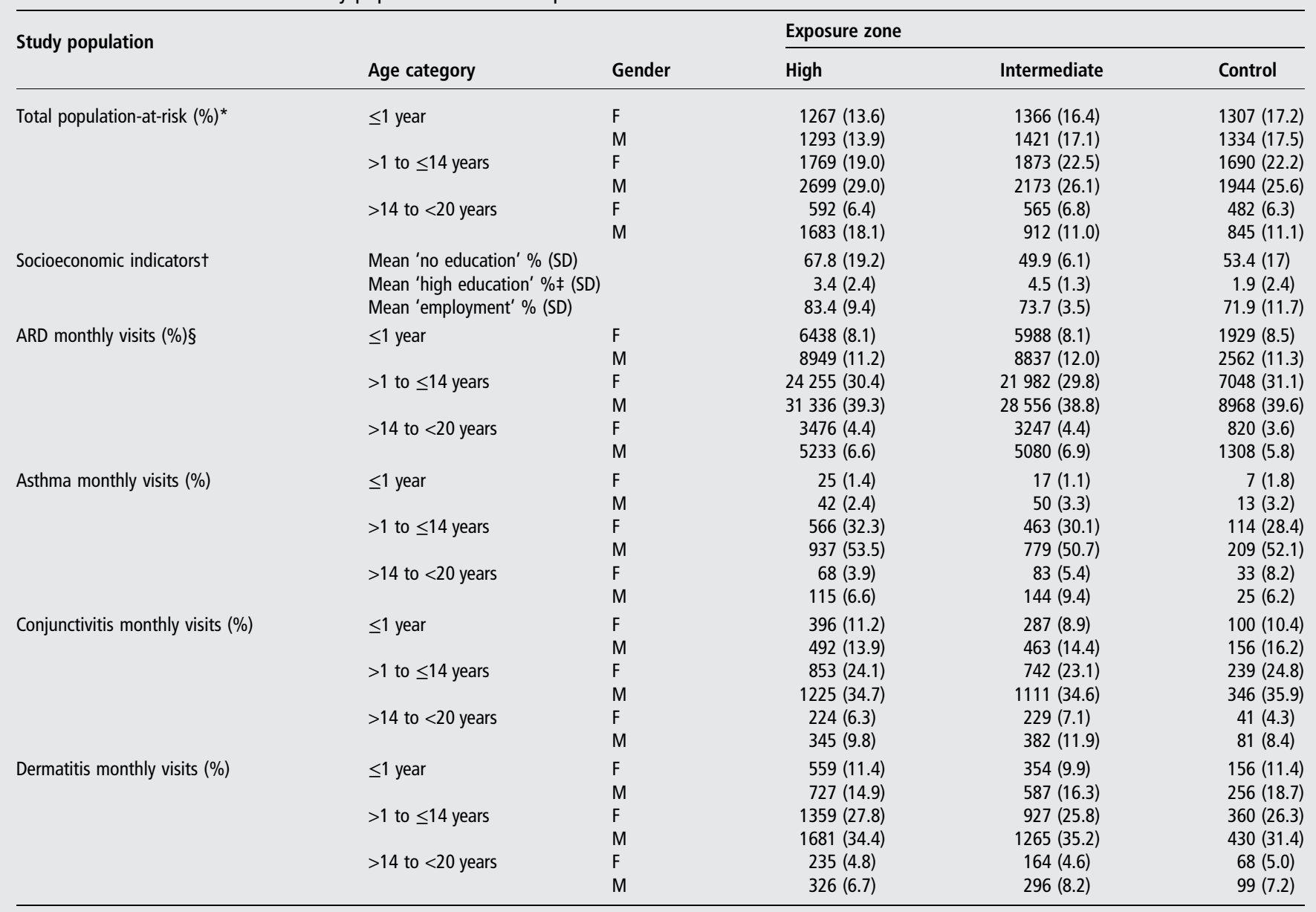

Population ages $<20$ years, Sohar and Liwa provinces, Oman, 2006-2010.

*Percentage to the total counts in the exposure zone.

tShowing the mean percentage of the respective SES in the villages of each exposure zone with the SD.

¥High education: individuals with a bachelor's degree and above.

§Percentage to the total counts in the exposure zone. The total number of villages in the study is $59 ; 8$ are located in the high exposure zone; 4 are located in the intermediate zone;

the remaining 47 smaller villages are located in the control zone.

ARD, acute respiratory diseases; F, female; $M$, male; SES, socioeconomic status.

proximity to a new industrial park in Oman. The findings of the study suggested an increase of more than twofold to threefold in the risk of respiratory and allergic diseases among a young population living within $10 \mathrm{~km}$ of the industrial park. This geographical dispersion of pollution could be explained by the unfavourable geographic location of SIZ. A recent

Table 2 Multivariable analysis* of acute respiratory diseases, asthma, conjunctivitis and dermatitis incidencet, in association with the high and intermediate exposure zones

\begin{tabular}{lll}
\hline Diseases & $\begin{array}{l}\text { High } \\
\text { RR }(95 \% \mathrm{CI})\end{array}$ & $\begin{array}{l}\text { Intermediate } \\
\text { RR }(95 \% \mathrm{CI})\end{array}$ \\
\hline ARD & $2.6(2.3$ to 2.8$)$ & $2.3(2.1$ to 2.6$)$ \\
Asthma & $3.6(3.0$ to 4.4$)$ & $3.7(3.1$ to 4.5$)$ \\
Conjunctivitis & $3.1(2.8$ to 3.4$)$ & $3.2(2.9$ to 3.5$)$ \\
Dermatitis & $3.0(2.7$ to 3.3$)$ & 2.5 (2.3 to 2.7$)$ \\
\hline
\end{tabular}

Study population of ages $<20$ years, Sohar and Liwa provinces, Oman, 2006-2010. ${ }^{*}$ Adjusted for time trend.

†Age and gender standardised according to census population figures for 2010 .

$A R D$, acute respiratory diseases $\mathrm{Cl}$, confidence interval; RR, risk ratio. meteorological study by Al-Khadouri et $a l^{33}$ reported that the location of SIZ promotes the formation of a stagnant air mass that could travel more than $10 \mathrm{~km}$ inland.

Owing to the lack of pollutant emission data for this study, we used the proximity to source for our exposure classification. This approach has been used frequently in many environmental epidemiological, ${ }^{5}{ }^{21-23}$ environmental policies, ${ }^{24} 25$ and environmental justice studies. ${ }^{27}$ This extensive use of the proximity method as an exploratory tool for scoping health effects around industrial areas is mainly because it is simple, fast and more economical, and in our study it was the only way to assess the health effects of this rapidly developing industrial setting.

Our results agree with the existing epidemiological evidence regarding the health effects of the respiratory tract system, ${ }^{5}$ eye ${ }^{6}$ and skin $^{7}$ of children living near a petrochemical complex. These industries are known to emit a number of environmental pollutants including $\mathrm{SO}_{2}$, nitric oxides $\left(\mathrm{NO}_{\mathrm{x}}\right)$ and volatile organic compounds, ${ }^{34}$ which have been shown to cause skin and mucosal lining irritation, especially of the eyes and respiratory tract. ${ }^{35}$ Several epidemiological studies reveal that children living in the proximity of aluminium and iron smelters are prone to impaired lung function, ${ }^{9}$ increased hospitalisation from 
Table 3 Multivariable analysis* of acute respiratory diseases, asthma, conjunctivitis and dermatitis incidencet, in association with the combined exposure zone

\begin{tabular}{|c|c|}
\hline Exposure groups & $\begin{array}{l}\text { Combined } \ddagger \\
\operatorname{RR}(95 \% \mathrm{CI})\end{array}$ \\
\hline \multicolumn{2}{|l|}{ ARD } \\
\hline Overall & 2.5 (2.3 to 2.7$)$ \\
\hline Males & 2.3 (2.1 to 2.7$)$ \\
\hline Females & $2.6(2.3$ to 2.9$)$ \\
\hline$\leq 1$ year & $2.6(2.4$ to 2.9$)$ \\
\hline$>1$ to $\leq 14$ years & 2.4 (2.2 to 2.6$)$ \\
\hline$>14$ to $<20$ years & 2.6 (2.3 to 3.1$)$ \\
\hline$\leq 50 \%$ 'no education' strata§ & $2.3(2.1$ to 2.6$)$ \\
\hline$>50 \%$ 'no education' strata & $2.7(2.4$ to 3.0$)$ \\
\hline$\leq 50 \%$ 'high education' strataๆ & $2.6(2.4$ to 2.9$)$ \\
\hline$>50 \%$ 'high education' strata & 23 (2.1 to 2.5$)$ \\
\hline$\leq 50 \%$ 'employment' strata & $2.6(2.4$ to 2.9$)$ \\
\hline$>50 \%$ 'employment' strata & 2.3 (2.1 to 2.5$)$ \\
\hline \multicolumn{2}{|l|}{ Asthma } \\
\hline Overall & 3.7 (3.1 to 4.5$)$ \\
\hline Males & $3.6(2.8$ to 4.7$)$ \\
\hline Females & $3.8(2.9$ to 5.1$)$ \\
\hline$\leq 1$ year & $3.6(2.2$ to 6.1$)$ \\
\hline$>1$ to $\leq 14$ years & 4.6 (3.8 to 5.7 ) \\
\hline$>14$ to $<20$ years & 2.6 (1.9 to 3.5$)$ \\
\hline \multicolumn{2}{|l|}{ Conjunctivitis } \\
\hline Overall & 3.1 (2.9 to 3.5$)$ \\
\hline Males & $2.9(2.5$ to 3.3$)$ \\
\hline Females & 3.5 (3.1 to 4.1$)$ \\
\hline$\leq 1$ year & 3.3 (2.8 to 3.8$)$ \\
\hline$>1$ to $\leq 14$ years & $3.0(2.7$ to 3.4$)$ \\
\hline$>14$ to $<20$ years & 3.8 (3.0 to 4.8$)$ \\
\hline \multicolumn{2}{|l|}{ Dermatitis } \\
\hline Overall & 2.7 (2.5 to 3.0$)$ \\
\hline Males & $2.6(2.3$ to 3.0$)$ \\
\hline Females & $2.9(2.6$ to 3.3$)$ \\
\hline$\leq 1$ year & $2.8(2.5$ to 3.3$)$ \\
\hline$>1$ to $\leq 14$ years & $3.0(2.7$ to 3.3$)$ \\
\hline$>14$ to $<20$ years & 2.5 (2.0 to 3.1$)$ \\
\hline \multicolumn{2}{|c|}{$\begin{array}{l}\text { Study population of ages <20 years, Sohar and Liwa provinces, Oman, 2006-2010. } \\
\text { *Adjusted for time trend. } \\
\text { †Age and gender standardised according to census population figures for } 2010 \text {. } \\
\text { †Including high and intermediate zones, with control zone as the reference. } \\
\text { §Stratification by SES was only carried out for ARD due to insufficient numbers in } \\
\text { other disease definitions. } \\
\text { १High education determines as having a bachelor degree or higher. } \\
\text { ARD, acute respiratory diseases Cl, confidence interval; RR, risk ratio; } \\
\text { SES, socioeconomic status. }\end{array}$} \\
\hline
\end{tabular}

respiratory disease, ${ }^{8}$ and increased allergic sensitisation and allergic symptoms, ${ }^{10}$ most likely related to emitted aluminium and fluoride compounds, $\mathrm{SO}_{2}, \mathrm{NOx}$ and heavy metals. ${ }^{34}$

The findings of this study did not show any difference in exposure-disease associations by age groups; an indication of a greater association between asthmatic events and exposure among ages $\leq 14$ years was observed. This is most likely due to the susceptibility of these age groups because of less mature respiratory and immune systems, and also because children spend most of their time outdoors and breathe 50\% more air per body mass compared with adults. ${ }^{3}$

A greater number of males aged $>1$ to $<20$ years was noted in the exposure zones for both study and at-risk population groups. Gender differences were not as pronounced in the
Table 4 Multivariable analysis* of acute respiratory disease and asthma follow-upst in association with the combined exposure zoneł

\begin{tabular}{|c|c|}
\hline Exposure groups & $\begin{array}{l}\text { Combined§ } \\
\text { RR }(95 \% \mathrm{Cl})\end{array}$ \\
\hline \multicolumn{2}{|l|}{ ARD follow-ups } \\
\hline Overall & 2.5 (2.8 to 2.7 ) \\
\hline Females & 2.5 (2.2 to 2.9 ) \\
\hline Males & 2.4 (2.1 to 2.8 ) \\
\hline$\leq 1$ year & 2.9 (2.6 to 3.2$)$ \\
\hline$>1$ to $\leq 14$ years & 2.4 (2.2 to 2.7$)$ \\
\hline$>14$ to $<20$ years & 2.5 (2.1 to 2.8$)$ \\
\hline \multicolumn{2}{|l|}{ Asthma follow-ups } \\
\hline Overall & 3.2 (2.5 to 4.0$)$ \\
\hline Females & 3.2 (2.3 to 4.4$)$ \\
\hline Males & 3.1 (2.3 to 4.2 ) \\
\hline$\leq 1$ year & $4.4(1.9$ to 10.1$)$ \\
\hline$>1$ to $\leq 14$ years & 3.5 (2.8 to 4.4$)$ \\
\hline$>14$ to $<20$ years & 2.5 (1.6 to 3.9$)$ \\
\hline \multicolumn{2}{|c|}{$\begin{array}{l}\text { Study population of ages <20 years, Sohar and Liwa provinces, Oman, 2006-2010. } \\
\text { Results are also stratified by age category and gender. } \\
\text { *Adjusted for time trend. } \\
\text { tFollow-ups were defined as any repeated patients' visits within } 1 \text { month of two 'new } \\
\text { event' visits. } \\
\text { ¥Age and gender standardised according to census population figures for } 2010 \text {. } \\
\text { §Including high and intermediate exposure zones, with control zone as the reference. } \\
\text { ARD, acute respiratory diseases Cl, confidence interval; RR, risk ratio. }\end{array}$} \\
\hline
\end{tabular}

control zone. To understand these patterns, we analysed the Omani census data of 2010 to compare the study population structure with the entire Omani population. The results suggested that the difference in the gender ratio in the study area starts from ages 10 to 14 years, a phenomenon not observed in the entire Omani population. One possible explanation for this greater number of young males in the study area might be due to the increasing labour force migration to this industrial area. This was also supported by the World Bank statistics of 2009, which showed that $87 \%$ of the young (aged 15-24 years) labour force in Oman was males. ${ }^{36}$

This is the first epidemiological study carried out in Oman that assessed the health of children living in proximity of an industrial complex. Similar studies elsewhere confirm our findings of adverse health effects among the young population and children living in the proximity of industrial settings. ${ }^{5-10}$ This evidence is, however, limited as highlighted by a recent review by Pascal et al ${ }^{11}$ which identified only 17 such studies globally. Therefore, we believe that the contribution of this study is important from a country, regional and global perspective. The findings of this study, in corroboration with the limited previous evidence, are particularly important from the perspective of the shift in environmental burden of disease from developed to developing countries. The accelerated need for economic development in many developing countries has led to the movement of the industrialisation trend from developed to developing countries. This has negatively affected the state of environment and health in these countries, particularly due to the lack of strict environmental and public health policies. ${ }^{2}$ In Oman, this inevitable industrial development has potential disadvantaged environmental situations, which may also contribute to further adverse health in population. The rapid pace of this industrial development trend requires the establishment and strengthening of environmental and public health systems in the country. We believe that the use of a precautionary principle to protect 
public and community health around any new industrial parks in Oman would be an appropriate early step to protect population health by the great environmental and health risks posed by this rapid industrial development. ${ }^{37}$ As a preventive measure, the Omani government has planned to displace the population in proximity of the SIZ industrial park to a different residential area. This measure, involving large economic costs, ${ }^{38}$ has potential sociocultural and economic implications for the displaced population, which merit further consideration. Future intervention programmes that focus on health protection need to consider these sociocultural factors, in addition to proper planning for environmental monitoring and control.

A few limitations of this study need to be recognised. Owing to the absence of emission data, we used the proximity to source for our exposure classification. The use of this approach might introduce misclassification bias when assigning exposure to population groups as pollutants do not respect boundaries. ${ }^{39}$ However, we tried to minimise this bias by assessing the potential extent of the pollutant spread utilising wind roses and dispersion model. These distances were also confirmed by similar definitions in previous epidemiological and policy studies. ${ }^{5} 31$ Another source of bias was potentially due to the study population loss to private healthcare. However, we think that this source of bias is small in our study, after excluding Sohar city from the analyses. There is great provision and uniform distribution of state health centres (large and medium) in exposure and control zones, which ensure easy access to free healthcare, and only a very limited number of small private clinics (only 3 from a total of 51 private clinics in the larger district). ${ }^{40}$ Also, excluding Sohar city from the analyses did not affect the study results, confirming the robustness of the data. The use of morbidity healthcare visit data could introduce inaccuracy in defining health outcomes, due to physician inaccuracies in diagnosis, patient comorbidities and the parents threshold to seek medical help for their children. ${ }^{41}$ The latter also depends on sociocultural factors and on accessibility to healthcare. While other factors are more difficult to control in an epidemiological study, the uniformly distributed state health institutions in the study area ensured easy accessibility and most likely uniform reporting and diagnosis of the health conditions studied here.

\section{CONCLUSION}

This study is the first environmental health study conducted in Oman to investigate health effects in children living near an industrial complex. This study would hope to mark the start of

\section{What is already known on this subject}

Living in proximity to industrial establishments is associated with adverse health in populations.

\section{What this study adds}

- This study is the first environmental epidemiological study in Oman that assessed the link between proximity to an industrial park and health in a young population.

- The study adds to the currently limited global evidence on the link between proximity to industry and child health. subsequent environment and health research and monitoring, and to assist in building up evidence for public health practice and environmental health policy in Oman. We also hope that these findings will contribute to a triggering of preventive actions and public health intervention programmes, as well as to global evidence on the effects of industrial development and child health.

\section{Twitter Follow Adil Al-Wahaibi at @adilsaidwahaibi}

Acknowledgements The authors wish to thank the considerable contributions from Dr Salim Al-Wahaibi and Dr Hamad Al-Adawi for their help in health data acquisition. The authors also wish to thank Professor Sabah Ahmed Abdul-Wahab Al-Sulaiman (Sultan Qaboos University, Oman) and Joseph S Scire (exponent) for their assistance in the CALPUFF modelling.

Contributors AA carried out the literature review, data collection, design methodology, analysis and paper drafting. AZ supervised and made substantial contributions to the design of the study, analysis, drafting of the paper and revising it critically and also gave the final approval of the version to be published.

Funding AA was funded by the Ministry of Health, Oman through a scholarship for his Doctor of Philosophy (PhD) degree.

\section{Competing interests None declared.}

Ethics approval Ministry of Health Oman and Brunel University Ethical Committee. Provenance and peer review Not commissioned; externally peer reviewed.

Open Access This is an Open Access article distributed in accordance with the Creative Commons Attribution Non Commercial (CC BY-NC 4.0) license, which permits others to distribute, remix, adapt, build upon this work non-commercially, and license their derivative works on different terms, provided the original work is properly cited and the use is non-commercial. See: http://creativecommons.org/ licenses/by-nc/4.0/

\section{REFERENCES}

1 Burki TK. Twice as bad: new estimates for mortality from air pollution. Lancet Respir Med 2014;2:355

2 McMichael AJ. The urban environment and health in a world of increasing globalization: issues for developing countries. Bull World Health Organ 2000;78:1117-26.

3 Schwartz J. Air pollution and children's health. Pediatrics 2004;113:1037-43.

4 Prüss-Üstün A, Corvalán C. Preventing disease through healthy environments. World Health Organization, 2006. (cited Apr 2014) http://www.who.int/entity/quantifying_ ehimpacts/publications/preventingdisease.pdf?ua=1

5 Wichmann FA, Müller A, Busi LE, et al. Increased asthma and respiratory symptoms in children exposed to petrochemical pollution. J Allergy Clin Immunol 2009;123:632-8.

6 Yang CY, Wang JD, Chan CC, et al. Respiratory and irritant health effects of a population living in a petrochemical-polluted area in Taiwan. Environ Res 1997;74:145-9.

7 Papadimitriou EA, Riza E, Pililitsis L, et al. Different effects of area of residency in atopic disorders and spirometric indices in children. J Public Health 2012;20:577-84.

8 Lewin A, Buteau S, Brand A, et al. Short-term risk of hospitalization for asthma or bronchiolitis in children living near an aluminum smelter. J Expo Sci Environ Epidemiol 2013;23:474-80.

9 Spektor DM, Hofmeister VA, Artaxo P, et al. Effects of heavy industrial-pollution on respiratory-function in the children of Cubatao, Brazil-a preliminary-report. Environ Health Perspect 1991;94:51-4

10 Wilhelm M, Eberwein G, Hoelzer J, et al. Influence of industrial sources on children's health-hot spot studies in North Rhine Westphalia, Germany. Int J Hyg Environ Health 2007;210:591-9.

11 Pascal M, Pascal L, Bidondo M-L, et al. A review of the epidemiological methods used to investigate the health impacts of air pollution around major industrial areas. J Environ Public Health 2013;2013:737926.

12 Al-Wahaibi A, Zeka A. Health impacts from living near a major industrial park in Oman. BMC Public Health 2015;15:524.

13 Ezzati M, Kammen DM. Quantifying the effects of exposure to indoor air pollution from biomass combustion on acute respiratory infections in developing countries. Environ Health Perspect 2001;109:481-8.

14 Campbell H, Armstrong JR, Byass P. Indoor air pollution in developing countries and acute respiratory infection in children. Lancet 1989;1:1012.

15 Brim SN, Rudd RA, Funk RH, et al. Asthma prevalence among US children in underrepresented minority populations: American Indian/Alaska Native, Chinese, Filipino, and Asian Indian. Pediatrics 2008;122:e217-22.

16 Loyo-Berrios NI, Irizarry R, Hennessey JG, et al. Air pollution sources and childhood asthma attacks in Catano, Puerto Rico. Am J Epidemiol 2007;165:927-35. 
17 Gruchalla RS, Pongracic J, Plaut M, et al. Inner City Asthma Study: relationships among sensitivity, allergen exposure, and asthma morbidity. J Allergy Clin Immunol 2005; 115:478-85.

18 Gerald LB. Changes in environmental tobacco smoke exposure and asthma morbidity among urban school children. Chest 2009;135:911-16.

19 Chang CJ, Yang HH, Chang CA, et al. Relationship between air pollution and outpatient visits for nonspecific conjunctivitis. Invest Ophthalmol Vis Sci 2012;53:429-33.

20 Solé D, Camelo-Nunes IC, Wandalsen GF, et al. Prevalence of symptoms of asthma rhinitis, and atopic eczema in Brazilian adolescents related to exposure to gaseous air pollutants and socioeconomic status. J Investig Allergol Clin Immunol 2007:17:6-13.

21 Briggs D. Environmental measurement and modelling: geographical information systems. In: Nieuwenhuijsen MJ, ed. Exposure assessment in occupational and environmental epidemiology. Oxford University Press, Incorporated 2003. pp. 60-70.

22 Sarov B, Bentov $Y$, Kordysh E, et al. Perinatal mortality and residential proximity to an industrial park. Arch Environ Occup Health 2008;63:17-25.

23 Yang CY, Chang CC, Chuang HY, et al. Increased risk of preterm delivery among people living near the three oil refineries in Taiwan. Environ Int 2004;30:337-42

24 U.S. Environmental Protection Agency. Framework for cumulative risk assessment. Washington DC: 2003:136p.

25 Health and Safety Executives. Planning advice for developments near hazardous installations. London: 2011:27.

26 Dayal H, Gupta S, Trieff N, et al. Symptom clusters in a community with chronic exposure to chemicals in two superfund sites. Arch Environ Health 1995:50:108-11.

27 Perlin SA, Setzer RW, Creason J, et al. Distribution of industrial air emissions by income and race in the United States: an approach using the toxic release inventory. Environ Sci Technol 1995;29:69-80.

28 Greaves WW, Rom WN, Lyon JL, et al. Relationship between lung cancer and distance of residence from nonferrous smelter stack effluent. Am J Ind Med 1981;2:15-23.
29 Linos A, Blair A, Gibson RW, et al. Leukemia and non-Hodgkin's lymphoma and residential proximity to industrial plants. Arch Environ Health 1991;46:70-4.

30 Kimbrough R, LeVois M, Webb D. Survey of lead-exposure around a closed lead smelter. Pediatrics 1995:95:550-4.

31 Tanyanont W, Vichit-Vadakan N. Exposure to volatile organic compounds and health risks among residents in an area affected by a petrochemical complex in Rayong, Thailand. Southeast Asian J Trop Med Public Health 2012;43:201-11.

32 EPA Victoria. Recommended separation distances for industrial residual air emissions. Victoria, 2013. http://www.epa.vic.gov.au/our-work/publications/ publication/2013/march/1518

33 Al-Khadouri A, Al-Yahyai S, Charabi Y. Contribution of atmospheric processes to the degradation of air quality: case study (Sohar Industrial Area, Oman). Arab J Geosci 2014:8:1623-33.

34 Nielsen OK. EMEP/EEA air pollutant emission inventory guidebook. Radcliffe Publishing: Luxembourg, 2013.

35 Patnaik P. A comprehensive guide to the hazardous properties of chemical substances. John Wiley \& Sons, 2007.

36 World Bank. World development indicators. 2014:1-136. (cited Apr 2014) http:/l data.worldbank.org/sites/default/files/wdi-2014-book.pdf

37 Martuzzi M, Tickner JA. The precautionary principle: protecting public health, the environment and the future of our children. WHO Regional Office for Europe, 2004:209. (cited Apr 2014) http://www.euro.who.int/_data/assets/pdf_file/0003/ 91173/E83079.pdf

38 Oman Observer. RO 500 million city to come up in Liwa. Oman Observer, 2014. (cited Apr 2014) http://omanobserver.om/ro-500-million-city-to-come-up-in-liwa/

39 Rothman KJ, Greenland S, Lash TL. Modern epidemiology. 3rd edn. Philadelphia: Wolters Kluwer Health/Lippincott Williams \& Wilkins, 2008.

40 Ministry of Health. Annual health report. Muscat: Ministry of Health, 2012. https:/l www.moh.gov.om/documents/274609/275102/CH10Y13.pdf/19471826-353548b6-84c1-d350e7c5412f

41 Donaldson LJ, Scally G. Donaldsons' essential public health. 3rd edn. Radcliffe Publishing: Abingdon, 2009. 